punto org

General Editor Luigi Maria Sicca

21 
MARIA LUSIANI

\title{
DISCOURSES OF PLANNING
}

\author{
preface \\ Luca Zan \\ afterword \\ Ann Langley
}

Editoriale Scientifica

Naples 
All rights reserved

(C) Copyright April 2016 by Editoriale Scientifica s.r.l.

Via San Biagio dei Librai, 39 - 80138 Naples

www.editorialescientifica.com info@editorialescientifica.com

ISBN 978-88-6342-922-0 
For Luca and for Clara 


\section{Contents}

15 Thinking means and ends critically: our internationalization of managerial research Luigi Maria Sicca

19 Preface

Luca Zan

23 1. Introduction

$23 \quad 1.1$ Foreword: what the book is about and why read it

251.2 Presentation of the book: what the book is about-more precisely

Part i. Bridging Perspectives

35 2. Introduction to part I

37 3. Planning: definition, history, current trends

393.1 The design school, the learning school and the practice turn

$42 \quad 3.2$ The roles of planning

$42 \quad 3.2 .1$ Decision realm

44 3.2.2 Process realm

$52 \quad 3.3 \quad$ Fall or rise of planning?

55 4. The changing public sector: managerialism, professionalism and beyond

564.1 Public sector reform: in the substance or in the rhetoric?

584.2 Profession-management tensions in the changing public sector

59

4.2.1 Resistance 
61

63

69
4.2.2 Decoupling

4.2.3 Hybridization

5. A discourse analysis perspective

5.1 The discursive turn in management studies

5.2 Between discourse and practice

5.2.1 Power of discourse

5.2.2 Discourse and cognitions

5.2.3 Discourse as a tool

Part it. Research Design

89 6. Introduction to part II

91 7. The empirical questioning

95 8. The broad context: The healthcare reform in Italy

978.1 Decentralizing healthcare services

$98 \quad 8.2$ Managerializing healthcare services

98 8.2.1 Managerialization at the system level: the re-design of the NHS

8.2.2 Managerialization at the organizational level: planning practices

99

8.2.3 Managerialization at the individual level: 'medical-manager'

101 9. The case: Omega and its planning system

1019.1 Organizational profile

1029.2 The planning system

107 10. Methodology

$110 \quad 10.1$ Case selection and research object specification

11210.2 Data collection

$115 \quad 10.3$ Coding scheme

$118 \quad 10.4$ Analytical procedure

PART III. Evidence From THE FIELD:

$1^{\text {ST }}$ ORDER DESCRIPTIVE ANALYSIS

123 11. Introduction to Part III 
125 12. Strategic planning

12.1 Omega's representation of strategic planning

12.2 The plan (2010-2012)

12.3 The observed strategic planning process 12.3.1 Formulation of the strategic plan 12.3.2 Presentation of the strategic plan 12.3.3 Uses of the strategic plan

12.4 Insights on strategic planning

13. Budgeting

13.1 Omega representation of budgeting

13.2 The budget file

13.3 The observed budgeting process

13.3.1 Pre-negotiation budget data analysis

13.3.2 Negotiation

173

13.4 Insights on budgeting

14. Project management

14.1 Omega representation of project management

14.2 The projects

14.3 The observed project management process

14.3.1 Setting up the project proposal file

14.3.2 Projects' selection

14.3.3 Project planning

14.3.4 Work progress reporting

14.3.5 Final reporting

14.4 Insights on project management

Part iv. Evidence from the field:

2ND ORDER INTERPRETIVE ANALYSIS

201 15. Introduction to part IV

203 16. Dominance of planning?

$203 \quad 16.1$ Findings-organizational level

$206 \quad 16.2$ Findings-individual level

$217 \quad 16.3$ Summary 
221 17. Cognitions of planning

$221 \quad 17.1$ Findings

17.1.1 Actors' views on strategic planning

234

17.1.3 Actors' views on budgeting

241

18. From discourse to practice

18.1 Findings

18.1.1 Resistance ("It's all about smoke and mirrors")

18.1.2 Absorption ("there is enthusiasm")

18.1.3 Decoupling

18.2 Summary

Part V. Pulling It All Together

263

19. Discussion

19.1 Apparent colonization

265

19.2 Dynamics of appropriation: the failure of formal planning as a decisional tool

19.3 What's left for planning? 19.3.1 The knowledge work value of planning 19.3.2 The social (boundary) value of planning

20. Conclusion

20.1 Contribution to the literature on planning

27520.2 Contribution to the literature on profession-management tensions

20.3 Contribution to discourse studies

27820.4 Practical implications

27920.5 Limitations and directions for future research

281 Appendix I: Interview protocols

285 Appendix II: Coding scheme 
303 Reference List

315 Acknowledgements

317 Afterword

Ann Langley

321 References

323 Index of names

327 punto org book series 


\section{Thinking means and ends critically: our internationalization of managerial research}

This book is the second published in English within our book series. Other books in English are scheduled to become available to the public in the short run. The decision to publish the same book series in different languages, so far Italian and English, is a very considered choice. A choice that is embedded in the DNA of our puntOorg project.

puntOorg pays great attention to the relationship between means and ends, both when we deal with organizational and managerial practices, and when we go to the root of organizational and managerial issues, investigating what lies under the way we do our research, questioning ourselves on the epistemological and methodological premises that, consciously or unconsciously, guide our work.

For this reason, we are aware that each language is a mean to an end. Each means is at the service of an end that, in the case of a language, is to explain our search results to the scientific community.

Being mindful of these fundamental issues, we are aware that carrying out research in Italian, English or in another language, is not neutral with respect to the objectives of the research itself.

Indeed, each mean is never neutral with regard to the end. Doing research and then publishing, in English, Italian, or for example, in Chinese or Russiåan, is not by definition the same thing. We are aware of this, and for this reason we believe that 
the coexistence of multiple languages within the same editorial project will challenge and animate the international debate on the relationship between means and ends, between instruments and objectives.

Being aware of how complex the relationship between means and ends always is (in the history of philosophy as well as in the theories and management practices), puntOorg places great importance on the processes (how to do), as well as on the results and performances (what to do/get).

The Working Paper Nursery is another editorial line alongside our book series, which follows this approach (http://www. puntoorg.net/en): we welcome research in its embryonic stage in order to enhance the growth process of each project, which is achieved through a non-anonymous mentoring relationship.

Mentor and mentee, together, cooperate openly throughout the life cycle of each research project born or raised in our Nursery in order to explore the underlying layers of processes and to reason together on how to do. We support and nurture research in order to explore our potential and win the international competition on top journals.

We believe that true success that leaves a significant trail of research in the long run, requires a slow, deep and detailed discussion on processes, on how to do.

The Working Paper Nursery, in addition to being an alternative option to the mainstream logic of anonymity in peer reviews (which we practice in our book series in line with the review processes of the major international publications), is also our way to give greater importance to reflection on the method. The method is "technique". Technique is a word that translates what in the ancient world was called "Art". And technique, as the "art" (how to do) translated and recovered from its meaning in the ancient world, allows us to give strength to what we do, even when do- 
ing research in the economic and managerial field. The source of this strength is in the investment of time and intellectual resources in how to do rather than only what to get.

We believe that the contemporary world, learning this lesson from the most common practices in the ancient world, has the urgent need to properly tackle questions related to the numerous crises through which we live, which are often labelled 'economic crises' but which on closer examination prove to represent first and foremost crises of thought.

And we believe that the crisis of thought can be often challenged through a commitment in addressing methodological issues, based on the ability of the scientific community to articulate critical thinking between means and ends.

Attention to the languages (and processes) used in the carrying out of research in the field of management is therefore a key asset of the method through which puntOorg offers an authentic internationalization of research practices.

We are aware that carrying out research means, by definition, having to deal with a Janus: he was Bifrons. And, for us, engaging in research means having to deal at the same time with a means and an end, looking at the future and the past, but also - as with the "God of beginnings and passages" - looking both inside and outside.

In this way, the book by Maria Lusiani (here published with a preface by Luca Zan, an afterword by Ann Langley and the cover illustration by Luca Carnevale), raises an issue that is at the root of puntOorg experiences by invoking the theme of the intensification of planning, which must be measured with the multiple rationalities that may be interacting when a change in practices is in place, and by proposing a methodology of research that is both rigorous and non-dogmatic.

Luigi Maria Sicca May, $25^{\text {th }}$, Naples, University Federico II 


\section{Preface}

Luca Zan*

A quick reference to the story of this work will help understanding its meaning. The book originates from Maria Lusiani's fieldwork for her Ph.D. dissertation. Why someone with a strong, substantive interest in arts organizations, and with a background in art management, will choose a hospital for her PhD fieldwork and dissertation? It took me a while to find an answer to such a question about Maria Lusiani: this could provide a way to make sense of this book as well.

At the beginning - I must confess - I was worried that she was simply going to leave the field of arts management. This would have been absolutely legitimate on her side - especially at early stages of your carrier, defining your exact field of interests can present huge discontinuities. For me however - as an active member of the arts management community in Italy - this would have resulted in a loss of potential resources.

The choice had a different meaning, and a bit more complex rationale, as I (think I) understood over time. On the one hand, there was a need of testing other fields: all in all, the world is not made only by arts organizations, and if you have a bachelor and a master degree in arts management there is a genuine curiosity in "smelling around", looking at what happens in other fields. In this sense arts management and healthcare management have

* Gioca Research Centre, Management Department, University of Bologna. 
a lot in common, particularly in countries ruled in a law driven way. In most countries they are deeply linked to the dynamics of public sector, with similar discourse on privatization, outsourcing, managerialization and so on. Despite their inner "technologies" (medicine vs arts) for several issues and contexts one could easily cut and paste the two terms from the same text, even in clever ways!

But more than communalities as public sector entities there is another crucial element that matters: art and health are professional organizations, where professional values - almost tacit, when not hidden - largely drive the attention and behavior of "good" professionals. This puts the two contexts in a very similar situation: in principle good professionals, focused on the values of their respective professions, do not care to budge, to compromise, to trade off (or to "trade") the universalistic nature of their professional values. Budgeting, and more generally managerial approaches, find historical and cultural resistance in these contexts, somehow perceived as a violation and intrusion in a tradition of professionalism dating centuries, if not millennia (e.g. Hippocratic Oath). And this "intrusion" started really so quickly, with Reagonomics and Thatcherism and the neoliberal wind and the end/decline of Keynesian world.

In such a condition, a non "cultural imperialist" understanding of management and accounting disciplines is helping professionals to learn to budge (and budget), still preserving substantive elements of the professional discourse, and the founding professional values. In this sense, looking at healthcare organizations is perhaps a pragmatic choice, for a $\mathrm{PhD}$ project. Given the aggregate relevance, the "managerialization" in the healthcare sector came earlier, with much stronger emphasis, probably with more effective results than what happed in the art/heritage sector. Here, in contrast, stronger resistance can be found by both professionals and the bureaucratic apparatuses (either al the municipal and the Ministry levels: the rise and fall 
of Pompeii autonomy being a paradigmatic example). This also addresses a possible research agenda for the future, to which this book could represent an initial step, focusing on a multidimensional comparison of the variety of processes of change in the last decades within an inter-national and inter-sectoral setting. E.g., how archaeologists in Italy were dealing with similar pressures compared to medical profession in Italy; and how this is different from what happened, say, in the UK?).

Indeed, the central interest in Maria Lusiani'sresearch is the issue of planning, planning inside a professional organization, apart from the sector. This book in a sense could be seen as a text on planning practices, where the hospital is one of the possible contexts, a sort of "accident" that has for sure deep impacts, but which is not the substantive element of interest of the author. (And as an arts manager scholar I am happy to see that several following works by the author are back to arts entities!).

Planning indeed seems to be a topic out of the interest of academic research in recent years, particularly (and paradoxically) in the strategic management field. Budgeting is even more so, something not very sexy for the international community of management scholars, despite any actor inside any organization tends to spend an enormous amount of his/her attention on budgeting issues. Here is the meaning and value of this book, looking in details (with perseverance) to practices in budgeting and planning activities, linking them to the nature of professional discourse and its evolution.

Doing a similar research is incredibly time consuming: indeed the book is based on extensive fieldwork, including a long period of participant observation (almost one year, every week, three full days a week). Given the "publish or perish" pressure that is increasingly affecting academic research (and researchers), this is not very usual to find, nor will it be in the future.

It is also hard to write: how you select the huge amount of qualitative data on day to day organizational life (not to say the 
time spent in transcribing original observations, coding interviews, working on raw qualitative data, aiming at making sense of what you were looking at)? Here a tough work of selection of qualitative data is needed, which is both time consuming and very painful/stressful: you know that what is left outside your next publication runs the risk of being lost in your hard disk, without being made available for anybody, forever.

And it is very difficult for the reader as well, almost impossible for the reader which is not interested on the specific contents and process, opportunistically looking only for "implications" and "generalization".

The research at the base of this book was carried out adequately; the writing is good. Now is your responsibility, dear reader. Read it, but only if you do care about what it is about: professionalism, planning \& budgeting, and above all practices. 